\title{
A construção material da midiatização: estudo dos procedimentos técnico-expressivos das minisséries Primo Basílio e Os Maias
}

\section{Imagens}

The material mediatization building: an investigation of the technical-expressive procedures from the TV mini-series O Primo Basílio and Os Maias

SOLANGE WAJNMAN

Professora do Programa de Pós-Graduação em Comunicação e Cultura Midiática da Universidade Paulista - UNIP.

<wajnman@aclnet.com.br>

MARIANA ChRISTINA DE FARIA TAVARES RODRIGUES

Professora do Instituto de Comunicação e Arte da UNA/MG.

<marianacftr@hotmail.com>

\section{RESUMO}

Trata-se de examinar a produção e veiculação dos cenários e figurinos de duas minisséries que se interconectam. Trabalhando historicamente, discute-se em âmbito mais geral, como a produção das minisséries se moderniza desde 1988 (Primo Basílio) até 2000 (Os Maias), época em que os recursos tecnológicos estão mais avançados e a organização de trabalho mais estruturada. A melhor qualidade da imagem, a busca de verossimilhança e a pesquisa histórica minuciosa, entre outros fatores, certamente contribuíram para o aprimoramento das estratégias de sedução da emissora. Ao mesmo tempo, em níveis mais específicos, busca-se compreender como os procedimentos tecnológicos e estéticos utilizados no tratamento do figurino se inserem nos processos de emergência da midiatização, processos estes, característicos de uma sociedade globalizada.

Palavras-chave: Televisão; Cenário; Figurino.

\section{ABSTRACT}

This work looks up through the production of the sceneries and costumes of two Brazilian TV mini-series, linked by their original author. Throughout a historically overview we discuss the modernization of production since 1988 (O Primo Basílio) to 2000 (Os Maias), when we can find advanced technological resources and a better structured production work organization. The better quality of image, the enhancement search for the period likeness, and the deep historical research, between others, has increased the seduction strategies of the television company. In parallel with a more specific look, we try to understand how the technological and aesthetical procedures used in the costume's creation and characterization insert themselves in the emergence of the mediatization, a process that by itself is characteristic of a globalized society.

KeYwords: Television; Scenery; Costumes. 
Z ste trabalho investiga as estratégias e os procedimentos técnico-expressivos $\amalg$ utilizados na construção e na exibição do figurino das minisséries Primo Basílio e Os Maias, ao mesmo tempo em que discute suas imbricações com os processos midiáticos do audiovisual em tempos de globalização. Para tanto, trataremos, antes de tudo, de introduzir os conceitos básicos que norteiam este trabalho. Por um lado, a noção de materialidade e condições da produção de presença e por outro o conceito de midiatização.

O primeiro campo de investigação implica em chamar atenção para a maneira material com que o figurino é produzido e causa impacto no telespectador. Como foi feita a produção? Como se constituiu? Quais os materiais, tecidos e formas foram utilizados nesta reconstituição do passado? Como a figurinista se apropriou das formas, cores e texturas da época e as recriou? A questão da materialidade neste trabalho se exprime não só do ponto de vista dos objetos materiais (cenário e, sobretudo, figurino) como também do ponto de vista epistemológico. Sistematizada por Gumbrecht (1998), e levando em conta o trabalho de vários autores tais como McLuhan, Benjamin, Derrida entre outros, a teoria da materialidade é uma teoria que se faz em torno dessa reconstrução da materialidade. Trata-se de compreender como as condições materiais condicionam e colaboram para a emergência dos sentidos.

Ao mesmo tempo tratamos daquilo que Gumbrecht (2011) nomeia de produção da presença. Tanto Huyssen (2000) quanto Gumbrecht observam que há um desejo de presentificação nas subsequentes vagas de culturas de nostalgia. No primeiro há uma discussão em torno da busca do passado como âncora em tempos de globalização e, no segundo, um convite para a investigação focada nos efeitos de presentificação. Gumbrecht observa que a julgar pelas práticas e fascínios do presente "as técnicas de presentificação do passado tendem [...] a enfatizar a dimensão do espaço - pois só em exibição espacial conseguimos ter a ilusão de tocar objetos que associamos ao 
passado" (2011, pp. 153-154). Relaciona a introdução destas técnicas com a crescente popularidade dos museus, bem como um interesse renovado na reorientação da subdisciplina histórica da arqueologia. E podemos ainda acrescentar os filmes e minisséries históricas que têm a televisão e o cinema como suporte. Ora, a especificidade das ficções históricas em relação às demais é que a questão da narrativa dramatiza o passado cotejando-o com os fatos históricos e situa o telespectador em um nível de vivência especial, próxima do fascínio.

Trata-se de uma tendência que se verifica a partir da segunda metade da década de 1980. No Brasil, a produção de filmes relacionados à memória e à identidade nacional assumiu maior complexidade a partir dos anos 90, quando se impõe como exigência o atendimento ao mercado consumidor internacional. A produção cinematográfica insere-se, portanto, na lógica de um mercado no qual o filme é uma mercadoria comercializada mundialmente no segmento de bens culturais, contexto no qual a globalização interfere nas próprias características de produção da cultura. Em decorrência, as produções tendem a perder o caráter local e assumem características que se adaptam aos diferentes públicos em distintas localidades.

Dentro de um contexto atual em que a memória se exporta e se globaliza - Os Maias, por exemplo, foi realizada em coprodução Brasil e Portugal - é razoável supor que mecanismos figurativos sejam incorporados de modo a aglutinar maior público. Em outras palavras, indagamos como os recursos expressivos vão se impregnando de alguns dos mecanismos da midiatização.

Para tanto, retemos de Muniz Sodré (2006) a conceituação de midiatização como articulação de instituições com as organizações de mídia, isto é, como articulação pautada por atividades regidas por finalidades tecnológicas e mercadológicas, além de culturalmente afinadas com uma forma ou um código semiótico específico. Outro autor muito útil para nossa discussão é Braga (2007), pois, além de discutir a questão 
da midiatização, nos sugere uma operacionalização para análise de fenômenos. O autor admite que o processo de centralidade e de hegemonia da mídia não é completo e que, evidentemente, são possíveis saídas criativas. Mas o ponto forte de sua reflexão é o instrumental conceitual passível de categorização. Assim, podemos aproveitar a sugestão do autor para os produtos midiáticos do campo do entretenimento e verificar até que ponto a cultura visual das minisséries também opera segundo estes mecanismos.

Para Braga, estes mecanismos são sobretudo: rapidez nas comunicações, abrangência geográfica e populacional, captura, objetivação, transformação transmissão e circulação de tipos de informações e comportamentos, e a possibilidade de usá-los diretamente em interações sociais. Tal lógica da cultura midiática, a qual a cultura visual das minisséries se subsumiria até certo ponto, segundo nossa hipótese, teria também como característica a circulação ampliada e descontextualizada das imagens e/ou sons, objetos e situações pelos meios de comunicação. Assim como esta cultura midiática a qual Braga se refere, a cultura visual das minisséries pautar-se-iam pela desreferenciação e abstração da experiência mais contextual. Assim, o acontecimento que era face a face e presencial torna-se, hoje, dentro desta lógica, um processo de abstração crescente. Braga lembra que a transição de abstração se potencializa a partir da interação da oralidade e da escrita para a midiatização, descontextualizando e desreferenciando o aqui e o agora.

\section{As condições de emergência da midiatização}

É provável que as condições de emergência para a midiatização residam estruturalmente nas condições gerais de melhoria da imagem e do sistema de operacionalização industrial que as acompanham. Renato Ortiz, Silvia Borelli, entre outros já observaram como a televisão na sua trajetória desde os anos 1960 veio abandonando a linguagem 
radiofônica que a caracterizava como um rádio com imagens. Sabe-se que cada vez mais, com os avanços tecnológicos, a televisão como veículo de imagem vem ganhando sua especificidade. Mas foi preciso todo um processo. Para Borelli:

[...] dos anos 50/60 a 70 observa-se significativas transformações relacionados à tecnologia, ao gerenciamento administrado, à qualificação dos profissionais, ao fortalecimento do setor de telecomunicações e ao modelo narrativo [...] nas décadas de 1950/60, destacavam-se os seguintes 'marcos': busca de uma linguagem televisual própria (distanciada da radiofônica,cinematográfica, teatral): narrativas melodramáticas, com tendência ao dramalhão, fabricação de produtos em bases mais artesanais que industriais; improvisação técnica e ausência de critérios para a divisão de trabalho; migração de produtores culturais-autores, diretores, atores e demais componentes do processo-originários de outros campos como rádio, teatro e cinema; grande número de telenovelas adaptadas de textos literários; processo experimental de formação de autores, diretores, atores e demais agentes. Já nos anos 70, as transformações estão vinculadas a um conjunto de 'acontecimentos' [...] tais como: aparecimento do videotape; câmaras filmadoras 'mais leves' e responsáveis por imagens de melhor qualidade; introdução da cor; investimentos no treinamento e formação de pessoal; processo efetivo de divisão do trabalho; transmissão em rede nacional (para algumas emissoras) e ação concatenadas entre setores das telecomunicações e potencialidades das novas tecnologias, em rápida ascensão no período."

(2011, p. 63) 
Todo esse processo tecnológico e organizacional pode ter sido responsável para a melhoria das telenovelas e, em especial, das minisséries. Uma das consequências desta melhoria é a aproximação da imagem da tela com o real. Isso não se dá somente no nível narrativo, no sentido em que as tramas de maneira progressiva se ancoram em realidades mais concretas, mas também no sentido fotográfico da imagem. Tudo isso favorece o processo de identificação do telespectador. Ao incorporar o ambiente externo além do estúdio, (como paisagens e ruas), a telenovela se distingue do teleteatro. E ao trabalhar com poucas tomadas de câmera e de maneira a manter a continuidade da imagem sem fragmentá-la como na telenovela, a minissérie se aproxima da linguagem cinematográfica. E enfim, com a introdução da tecnologia digital, em especial, a televisão como um todo parece estar em uma nova etapa.

Dentro desse contexto, as minisséries Primo Basílio (1988) e Os Maias (2001) se encontram em estágios diferenciados. Sob o ponto de vista da visualidade podemos dizer que apesar dos avanços de cenografia, especialmente com Mario Monteiro, cenógrafo de Primo Basílio, a qualidade visual avança, mas há ainda uma restrição com as técnicas, câmeras e iluminação. A força da narrativa ainda continua sendo a interpretação, como por exemplo, a atuação de Tony Ramos no momento em que descobre que sua personagem, Jorge, foi traída. São duas câmeras Ikegami que captam com maestria, por ângulos diferentes a dor e a raiva daquele momento. No caso de Os Maias, câmeras mais sofisticadas, edição eletrônica e efeitos de pós-produção implicam numa diluição dos personagens na estética da imagem. Observa-se assim que, em 2001, a televisão já aprimora a linguagem televisiva de modo que os recursos visuais integrem de maneira mais intrínseca à própria narrativa. Muito provavelmente devem ter sido estes efeitos que levaram Luís Fernando Veríssimo a comentar na apresentação do DVD que seguiu a minissérie: 
A câmera extraordinariamente móvel do Luiz Fernando Carvalho 'frequentou', mais do que retratou, a frívola Lisboa da época e todas as atmosferas do romance. Mas no fundo havia aquela progressão majestosa, desde a primeira cena, para o desenlace, a câmera andante nos levando como um lento tema trágico que repassa uma sinfonia. Nunca uma câmera de TV foi tão cúmplice e envolvente, nunca a TV foi tão romântica."

(Os Maias, 2004, DVD).

A preocupação com o detalhe dos objetos do contexto histórico também é grande, e aquilo que constitui sua particularidade. Como afirma um cenógrafo, consciente da importância do seu trabalho: "a minha preocupação ao montar o cenário não é decorar. Todas as coisas devem ter função no cenário, desde a parede, a colher que você pega, a estatueta. $\mathrm{O}$ aspecto se um objeto é da época ou não é da época, isto é fundamental" (Ortiz, 1988, p. 140). São esses detalhes dos cenários e figurinos que se tornam cada vez mais cientificamente construídos. São eles que podem conferir verossimilhança à narrativa. O que não impedirá os desvios conscientes como mostraremos mais adiante.

Dentro desse contexto do detalhe de objetos, a produção mais esmerada foi sem dúvida a de Os Maias. Os objetos de cena e os figurinos ratificam a sensação do passado. As cortinas pesadas do Ramalhete, os tapetes que cobrem todos os cômodos, a forma regrada e artística com que os pratos são distribuídos nas mesas para os jantares. A escolha dos objetos que trazem em si a lembrança de outros tempos: taças de design leve de vinho decoradas, os arranjos de flores de centro de mesa respeitando os cânones da decoração oitocentista, as velas acesas que oferecem aos ambientes uma luz amarelada 
e escura. Além disso, Os Maias, em especial, usou e abusou da linguagem tátil em seus objetos e texturas. Como observa Cardoso, a nova tecnologia

[...] dos processos de captação, transmissão e recepção da imagem, entre os quais se incluem o sistema digital e as telas de alta resolução, somados à aceitação dos efeitos naturais causados pela retícula eletrônica, como o do moiré, trouxeram para nossa tela as texturas extremamente detalhadas dos salões da aristocracia portuguesa da metade do século XIX, [...] as cores saturadas e contrastantes [...]."

(2008, p. 78)

Neste caso há um componente forte de efeito sinestésico. Os objetos em imagem solicitam a mistura dos sentidos: sente-se com os olhos aquilo que seria reservado ao toque; a tatilidade aveludada de um sobretudo ou a leveza de um vestido de seda da protagonista. Conhece-se pelos olhos o aconchego aristocrático dos tons de vermelho que o palacete dos aristocratas ostenta antes de seu discurso verbal. Ficamos sabendo do estilo de vida da elite portuguesa com nosso corpo. Dito de outro modo, a linguagem sinestésica dos objetos de cenário e figurino, intensificada pelos recursos de luzes e câmeras, desponta atualmente como uma característica da linguagem audiovisual das minisséries, em especial.

Além da construção desta sinestesia que culminará em Os Maias, outros processos de modernização da emissora facilitam a imersão do telespectador na imagem. São estes detalhes dos cenários e figurinos que também são cientificamente construídos. Trata-se dos próprios objetos que conferem verossimilhança à narrativa. 
Diferentemente de Os Maias, as cenas exteriores de Primo Basílio não foram feitas em Portugal, por demandar maior investimento financeiro. Elas foram reconstituídas em Bonsucesso (RJ) e gravadas em um terreno plano de Guaratiba (RJ), cidade cenográfica que antecede o Projac (Central Globo de Produção), em Jacarepaguá, também no Rio de Janeiro. Para muitas destas cenas, a solução foi o chroma key (recurso que permitiu a impressão de figura presencial e fundo projetado) e a técnica do newsmate (técnica que possibilita a colocação de uma imagem recortada por outra), essa última utilizada para a figuração do Teatro São Carlos, prédio barroco do século XVIII. Na opinião de António Casimiro (2009), cenógrafo português e consultor das duas minisséries, "os interiores dos ambientes queirozianos foram reproduzidos, mas a reconstituição desses ambientes nas cenas externas não foi bem feita".

\section{Construção de figurinos e midiatização}

O trabalho com os objetos do figurino tem se modernizado uma vez que a sua organização se aprimora ao longo da trajetória da televisão. Na verdade, a consolidação das telenovelas, seu reconhecimento junto aos telespectadores caminhou junto com a evolução técnica e conceitual de seu figurino. As telenovelas possuíam características fantasiosas, indefinição de épocas específicas, cenários e figurinos marcados pelo excesso, pela mistura de estilos, materiais e gêneros, com formas e construções tipicamente carnavalescas (Memória Globo, 2004, pp. 40-41). Atualmente o figurino é um trabalho que embora ainda traga a ambiguidade do artesanal torna-se, cada vez mais organizado, na pesquisa e produção.

Da mesma maneira que a fotografia e a produção do cenário, a construção dos figurinos de Os Maias marcou uma evolução na televisão brasileira. Houve um aprimoramento, já que contou com uma produção mais acurada e um investimento maior. Além de ter várias gravações em Portugal, os recursos eram maiores e o 
rigor com os trajes da época também. É o que observa a figurinista Beth Filipecki em Memória Globo:

Tive passe aberto no Museu do Traje (Lisboa), onde peguei na roupa, vi o seu peso. Era emoção pura. Eu realmente considero esse um trabalho maduro. Você não pode brincar de fazer Eça, não pode brincar de fazer dramaturgia da forma como a gente construiu a minissérie. Foi uma grande experiência. A busca pela modelagem perfeita, o tecido adequado, o caimento correto, o peso, a cor, a forma e o volume da silhueta estavam presentes como elementos essenciais do figurino."

(2007, p. 275)

No entanto, segundo nosso entendimento, mesmo em 1988 com O Primo Basílio, a pesquisa histórica e da tecnologia do vestuário do século XIX está bem feita. Tanto Os Maias como O Primo Basílio tiveram o cuidado em apresentar seus personagens com um figurino coerente com o que se usava no século XIX. Esta coerência vai dos detalhes explicitados por Eça de Queiroz no vestuário dos personagens, como ao sutil equilíbrio de tecidos, modelos, acessórios e ornamentos, característicos a cada um dos estratos sociais abordados pelo autor.

O figurino abriga tanto o visual das formas como o respeito a muitas das técnicas de construção das vestimentas da época. Tanto em Os Maias como em O Primo Basílio vemos o uso de colarinhos e punhos falsos, postos sobre a camisa masculina. Tal era o uso da época, que formalizava e empertigava os homens. E se verificarmos com um olhar mais atento os paletós dos personagens masculinos de Os Maias (Carlos da Maia, 
João Ega, Craft, Damaso e Castro Gomes), podemos perceber que a costura da peça sobre os ombros, a que une a parte da frente com a posterior, não é exatamente sobre o ombro, como nos paletós modernos, mas desloca-se enviesadamente um pouco para trás, acima das espáduas, como era de praxe nos paletós da época.

Mas a questão que importa aqui é verificar quando e como a emissora não respeita o conteúdo original de Eça de Queiroz e utiliza-se de artifícios. É a partir daí que poderemos "ler" os procedimentos e estratégias por onde a midiatização irá emergir. Retomamos nossa própria discussão quando dissemos que existiriam procedimentos que poderiam favorecer características da midiatização tais como desreferenciação, descontextualização, glamourização e atualização. Trata-se, no entanto, de conceitos muito próximos que muitas vezes poderão se entrelaçar, não havendo divisórias muito rigorosas entre eles.

Ao trazer a temática portuguesa do século XIX descrita criticamente por Eça de Queiroz, a emissora já porta uma situação de desreferenciação, per si, uma vez que a referência e identidade de Portugal são questionadas dentro do próprio romance. De fato, Portugal se colocava em uma situação de dependência em relação aos países europeus, como França e Inglaterra. Com uma identidade ainda colada aos louros da colonização do século XVI, Portugal permanecia em uma economia agrária enquanto seus vizinhos europeus já se inseriam na Revolução Industrial. Portugal orbitava em torno destes países também no que diz respeito às formas do bem viver, do vestir, do divertir e do proceder, no encalço da distinção social. Uma identidade globalizada europeia que será novamente retomada e atualizada para o contexto globalizado contemporâneo e veiculada pelos recursos técnico-expressivos da Rede Globo. Ora, a escolha de uma temática cujo alcance pretende-se global implica em características abrangentes. É desta maneira que a emissora vai, pela segunda vez (já que, como vimos, já existe um primeiro grau de indeterminação das referências portuguesas 
nos romances), exagerar na desreferenciação. E essa condição certamente é uma das estratégias da linguagem midiática. Linguagem essa que pode pertencer a todos, aproximar contextos e não ter vínculos com identidade nenhuma especificamente.

Segundo António Casimiro (2009), consultor português da Rede Globo para as minisséries, em O Primo Basílio os hábitos e costumes não foram muito bem estudados. O tipo de chapéu utilizado, por exemplo, apesar de ser português estava errado. Sobre a maneira de comer e os adereços, ele observa:

Não se comia com tanta abundância na manhã no mundo da burguesia. Era só pão com manteiga, pão torrado. O café da manhã não era assim. Muito abundante, frutas. Os almoços não eram assim. Não se comia bacalhau assim. E bacalhau era comida de pobre. As vezes de se tratar, maneira de se cumprimentar [...] A personagem Juliana, a cozinheira. A Marília Pêra apareceu com ornamentos de ouro, enfeitada, mas não era assim [...]."

É interessante nos determos particularmente nesta questão do brinco. A produção da TV Globo segue, quase que à risca, a descrição de Eça de Queiroz sobre Juliana, a criada de Luiza. Como no livro, o vídeo apresenta uma Juliana magra, seca, encovada, cansada. Seu figurino, a princípio, é constituído de pouquíssimas peças de roupa repetidas exaustivamente durante os capítulos. Seus trajes se modificam quando, chantageando Luiza, passa a receber desta algumas peças de roupas e acessórios. Grande parte dessas modificações é plausível na sua estilização para o vídeo. Entretanto, o que fica mais destoante são os brincos dourados que a criada exibe em todas as cenas. Ora, Queiroz, em nenhum momento faz menção ao uso dessa peça, que 
brilha e chama atenção na tela da televisão. Seu uso seria uma questão estética? Um pouco de brilho junto à face sombria da personagem, que usa roupas escuras e tem os cabelos escuros? Não temos essa informação, mas o fato é que os brincos usados por Juliana parecem-se bastante com os brincos da tradicional ourivesaria portuguesa, que exibem uma pequena variação de modelos, entre eles a arrecada, um tipo de brinco trabalhado em filigrana de ouro ou prata. Levando em conta a importância dos adornos e dos brincos, particularmente para a tradicional mulher portuguesa, inclusive considerando que os modelos das arrecadas são oriundos de similares populares, pode-se entender a utilização dos brincos pela personagem. E embora estes brincos não tenham sido descritos por Eça, o seu uso alia à personagem Juliana um objeto ícone do folclore português, um objeto que no imaginário popular se tornou conhecido através das imagens tradicionais divulgadas pela cultura de Portugal. Imagens estereotipadas que possam rapidamente ser reconhecidas por todos.

Além desta questão, ao trazer uma situação em que o figurino se situa em épocas históricas diferentes daquela em que Eça aponta, estamos, rigorosamente, tratando de descontextualização histórica. Para fins estilísticos e mesmo mantendo certa coerência com a narrativa, muitas vezes, os figurinistas ignoram o detalhe histórico em prol da narrativa. E isto ocorre nas duas minisséries.

Um exemplo: na sequência do namoro do casal Pedro da Maia e Maria Monforte em Os Maias, há um trecho incompatível com a realidade histórica e ergonômica que é a cena de Maria a balançar-se, e isto por causa da crinolina ${ }^{1}$ usada sob sua saia, vista em cena anterior. A saia volumosa da personagem era suportada pela crinolina, que em 1850 ainda não estava em uso, mas que ficou posteriormente consagrada como o modelo mais famoso da moda na época. Em Sintra, Maria é filmada a balançar-se ignorando o volume provido pelo conjunto saia/crinolina que tecnicamente a impediria de sentar com desenvoltura no balanço. Para esta cena, a crinolina foi subtraída. A minissérie 
Os Maias leva ao telespectador alguns exemplos de comportamento em sociedade que não se adequam às realidades físicas da época. Aproxima, gentilmente, sutilmente, a narrativa oitocentista de Queiroz aos hábitos mais comuns do contemporâneo. Atualizações, portanto.

\section{Considerações finais}

Foi nossa intenção neste trabalho compreender como os procedimentos tecnológicos e estéticos utilizados no tratamento do figurino de O Primo Basílio e Os Maias se inserem nos processos de midiatização típicos de nossa sociedade globalizada. Trabalhando pelo viés dos recursos expressivos e dentro de um contexto das condições de produção dessa midiatização mostramos como a racionalização e "cientificização" da emissora colaboram para este processo.

A globalização a que estão sujeitos os produtos televisivos desreferencia, descontextualiza e idealiza ou investe de glamour o dado histórico. A linguagem midiática tende a tornar o produto audiovisual algo compilado a partir de referências do senso comum. Como vimos, o brinco, ícone do folclore português, e a crinolina fora do seu tempo, entre vários outros elementos, são objetos que podem alterar a referência do contexto. Embora elementos do figurino, eles também fazem parte da linguagem da narrativa e informam história podendo alterá-la na sua referência e contexto. Este aspecto foi percebido por António Casimiro (2009), consultor da minissérie, quando nos ressaltou que

[...] a sociedade portuguesa na altura não era tão ostensiva. Os produtores brasileiros abusaram do luxo, talvez por exigência do diretor. Lisboa não era Paris, nem Londres, tampouco Viena de Áustria. Não ficou retratado o ambiente lisboeta do fim do século XIX e não quiseram aceitar muitos dos conselhos havidos, embora o resultado final fosse uma beleza." 
Resta saber agora como os produtos globalizados podem estar trabalhando para a popularização da cultura mundial. Em outras palavras, perguntamos: em que aspectos e dimensões os produtos de linguagem midiatizada podem estar agregando cultura? E certamente eles o fazem, mas aí já se trata de outra natureza. Natureza pós-moderna, sem dúvida.

\section{REFERÊNCIAS}

BORELLI, Silvia. Migrações narrativas em multiplataformas: telenovelas Ti-Ti-Ti e Passione. In: LOPES, Maria Immacolata Vassalo de et al. (Orgs.). Ficção Televisiva transmidiática no Brasil: plataformas, convergência, comunidades virtuais. Porto Alegre: Sulina, 2011.

BRAGA, José Luiz, Mediatização como processo interacional de referência. In: MÉDOLA, Ana Silvia Lopes Davi et al. (Orgs.). Imagem, visibilidade e cultura midiática. Livro da XV COMPÓS. Porto Alegre: Sulina, 2007.

CARDOSO, João Batista Freitas. A semiótica do cenário televisivo. São Paulo: Annablume, Fapesp, USCS, 2008.

CASIMIRO, Antônio. Consultor da Rede Globo para minisséries. Entrevistadores: Solange Wajnman e Mariana Christina de Faria Tavares Rodrigues. Lisboa: 2009. Gravador portátil digital (60 min.): estéreo.

GUMBRECHT, Hans Ulrich. Corpo e forma: ensaios para uma crítica não hermenêutica. Rio de Janeiro: UERJ, 1998.

. Produção de Presença: o que o sentido não consegue transmitir. Rio de Janeiro: Contratempo, 2011.

HUYSSEN, Andreas. Seduzidos pela memória: arquitetura, monumentos, mídia. Rio de Janeiro: Aeroplano, 2000. MEMÓRIA Globo. Entre tramas, rendas e fuxicos: o figurino na teledramaturgia da TV Globo. São Paulo: 2007. ORTIZ, Renato et al. Telenovela: História e produção. São Paulo: Brasiliense, 1988.

OS MAIAS [DVD]. Dirigido por Luiz Fernando Carvalho. Brasil: Globo Vídeo, 2004.

SODRÉ, Muniz. Eticidade, Campo Comunicacional e Midiatização. In MORAES, Denis. Sociedade Midiatizada. Rio de Janeiro: Mauad, 2006.

\section{NOTA}

1 A crinolina é uma armação feita com aros de metal que auxiliava a sustentar o excesso de circunferência e volume das saias usadas na Europa a partir da segunda metade da década de 1850, particularmente depois de 1856, quando começa sua comercialização. Maria em todas as cenas usa uma crinolina sob seus vestidos, antecipando para o ano de 1850 uma armação que veio a ser adotada pelas mulheres em 1856. 